\title{
COMPARATIVE STUDIES OF THE PROTEIN FRACTIONS FROM HUMAN GASTROINTESTINAL JUICES WITH PAPER ELECTROPHO- RESIS COMBINED WITH VARIOUS DETECTION METHODS
}

\author{
J. C. M. VERSCHURE \\ with the technical assistance of \\ Carla W. van der Schatr and Greta Hadders
}

Clinical-Chemical Laboratory of the Medical Clinics, State University, Utvecht (The Netherlands)

In recent years, electrophoretical studies of proteins in gastrointestinal juices have attracted increasing interest. Saliva was studied, mainly in relation to dental problems $^{1-7}$; gastric juice in relation to the intrinsic factor ${ }^{8-10}$ or physiological and pathological problems ${ }^{\mathbf{1 2 - 2 1}}$; bile ${ }^{\mathbf{2 4}}{ }^{\mathbf{2 5}}$, especially in relation to bile stone formation ${ }^{\mathbf{2 2}, \mathbf{2 3}}$ and the pancreatic juice of animals ${ }^{\mathbf{2 6 - 3 0}}$ for its protein composition and enzyme distribution. Separation of the fractions by means of paper electrophoresis was described in the papers $1,2,9,12,13,15,17-20,22-25,29,30$. Technical difficulties proved to be of major importance, therefore, the results of many investigations were incomparable, or contradictory as far as numbers, significance and the quantitative ratio of the protein fractions were concerned. Thus it is hardly possible as yet to describe the "normal pictures". With few exceptions (e.g. $\left.{ }^{21}\right)$, changes under pathological conditions have received little attention. Comparative studies on human material are practically lacking.

This paper deals with the results of more than 5000 paper electrophoresis diagrams of human gastrointestinal juices. We tried to find the optimal conditions for the separation of the fractions. A number of detection methods were developed and compared with various existing techniques. The discussion of the results will be restricted mainly to the qualitative aspects of the diagrams.

\section{MATERIAL AND METHODS}

The choice of methods was restricted to such simple procedures as could eventually be used for clinical routine purposes.

\section{Collection of samples}

Fresh samples, obtained at room temperature, were compared with those collected in ice. We collected whole saliva under various conditions; gastric juice with and without stimulation, carefully avoiding contamination with saliva; bile from postoperative fistulas only, from the gall-bladder only by puncture of the gail-bladder during surgery; pancreatic juice from postoperative fistulas only, and from extracts of fresh pancreas. The material was always filtered or centrifuged.

\section{Concentration}

This was done in small cellophane tubing (Dialysier Schlauch, Kalle \& Co, Wiesbaden-Biebrich), against $25 \%$ solutions of carboxymethyl cellulose or polyvinyl pyr- 
rolidone, in the refrigerator at $4^{\circ}$, mostly during 48 to $72 \mathrm{~h}$. A number of samples were freeze-dried and before use, they were made up to solutions of suitable concentration. When labelled with radio iodine, concentration was unnecessary, and the juices could be used directly or after dilution.

\section{Electrophoresis}

This was performed in horizontal strip cabinets, carrying Io strips pro run. Strips of $24 \times 4 \mathrm{~cm}$ were used at I $8 \mathrm{o} \mathrm{V}$, resulting in a potential gradient of about $7.5 \mathrm{~V} / \mathrm{cm}$. The time for electrophoresis was 2 to $4 \mathrm{~h}$. This proved to be sufficient in practically all cases.

Buffer solutions used were: barbital buffer $\mathrm{pH} 8.6$ and ionic strength 0.06 , or borate buffer pH 9.0 and ionic strength 0.12 as suggested by GLAss et al. ${ }^{21}$. Filterpaper: Whatman No. I and 3, and Nagell \& Macherey No. F 2I4 papers, the latter of which had relatively large pores.

Staining procedures

Proteins were stained either with azocarmine or with amido black. The latter was preferred, giving more distinct patterns.

Carbohydrate stain. The periodic acid stain of KoÏW AND GRÖNWALL ${ }^{31}$ was used, as modified by LAURELl AND SKOOG ${ }^{32}$.

Lipids and lipoproteins were stained with the common Sudan Black B stain of Swahn. For bilirubin a spray with diazo reagent was developed ${ }^{22}$.

For bile acids we developed a stain with vanillin-phosphoric acid ${ }^{22}$.

A mylase may be detected directly on the paper strips in the following way. After completing the run, the wet filterpaper strips are placed horizontally and allowed to dry at $37^{\circ}$. They are then sprayed lightly and evenly with an amylum solution containing $2 \mathrm{mg} / \mathrm{ml}$, kept for about ro min at $37^{\circ}$ and subsequently sprayed with an iodine solution of $0.05 \mathrm{~N}$. The strip stains dark blueish. A white band marks the place were the amylum was digested by amylase. The width of the band depends partly upon the time given for digestion. By shortening this time if the band is too board, a narrow band may be obtained, allowing accurate location of amylase in relation to other constituents. After marking the place of the amylase band with a pencil, the diagram may be used in the ordinary way for protein stain. The method is sensitive. Application of $3 \mathrm{U}$ amylase (Wohlgemuth) to the filterpaper suffices for a positive result (Fig. 3d).

Lipase activity may be detected in a way, similar to amylase. The wet paper strips are dried horizontally at room temperature. They are then dipped in a $0.1 \%$ solution of olive oil in petroleum ether (b.p. 60-80 ) and dried at room temperature. After allowing about 30 min for digestion, the diagrams are stained with Swahn's lipid stain. A light band in the blueish strip marks the place of lipase activity (Fig. 3e). The limit of sensitivity lays at $0.45 \mathrm{U}$ lipase on the strip.

Protenlytic activity. A suitable method for direct detection on the strip could not be developed. Various procedures were not sufficiently sensitive.

\section{Labelling of proteins with ${ }^{131} I$}

Active iodine is prepared by oxidation of iodide with iodate, using the procedure of VEALL et al. ${ }^{33}$ as modified by Foss ${ }^{34}$ for use in cerebrospinal fluid. 
Reagents. No. I: I\% human albumin in barbital or borate buffer. No. 2 : Carrierfree $\mathrm{Na}^{131} \mathrm{I}$, obtained from "Isotopen Lab. Philips-Roxane" Amsterdam. No. 3 : $\mathrm{I} \% \mathrm{KI}$ solution in aqua dest. No. 4: $\mathrm{I}_{\%} \mathrm{KIO}_{3}$ solution in aq. dest. No. $5: 0.2 \mathrm{~N} \mathrm{HCl}$. No. 6: $9 \% \mathrm{NaCl}$ solution in aq. dest. No. 7: O.I $\mathrm{N} \mathrm{Na}_{2} \mathrm{~S}_{2} \mathrm{O}_{3}$ solution.

Directly before labelling proteins, a solution with free ${ }^{131} \mathrm{I}$ is prepared by mixing $0.7 \mathrm{ml} \mathrm{No} .2$, 0.I $\mathrm{ml} \mathrm{No} .6$, $0.0 \mathrm{I} \mathrm{ml} \mathrm{No.} 3$ and $0.025 \mathrm{ml}$ No. 4 whereafter $0.05 \mathrm{ml}$ reagent No. 5 is added and after mixing, the solution is allowed to stand for $5 \mathrm{~min}$. The protein solutions to be labelled are brought to a $\mathrm{pH}$ value between 8 and io. The best results were obtained by titrating with o.I $N \mathrm{NaOH}$ to $\mathrm{pH} 8.5$. This step is essential. o.I $\mathrm{ml}$ of the protein solution is then mixed with o.I $\mathrm{ml}$ of the freshly prepared ${ }^{131} \mathrm{I}$ solution and kept at room temperature for $5 \mathrm{~min}$. The excess of ${ }^{131} \mathrm{I}$ is bound by adding $0.05 \mathrm{ml}$ reagent No. 7 and mixing. From this final solution $0.0 \mathrm{r}$ to $0.04 \mathrm{ml}$ are applied on the filter paper strips, the volume depending mainly upon the protein concentration of the solution to be analysed. From various methods of iodination ${ }^{35}$, the one described here gave the best results with gastrointestinal juices. The results were well reproducible.

Variation of virtually every experimental condition finally led to 4 different methods, the results of which will be shown.

Method $x$. Routine method as used for scrum clectrophoresis, adapted for gastrointestinal juices. The juices had to be strongly concentrated (often 50 to roo times). Whatman No. I cr 3 was used as filterpaper. Electrophoresis was performed in barbital buffer as described. The strips were stained with amido black or azocarmine.

Method 2. The procedure of GLASS et al. ${ }^{21}$ was followed exactly. However, we used cabinets for horizontal strips and for practical reasons the time of electrophoresis was $4 \mathrm{~h}$.

Method 3. The juices were used directly without concentration. They were latbelled with radio-iodine as freshly as possible. With this method diagrams could be made with only $3-5 \mu$ g of protein. Electrophoresis was carried out on Whatmann No. I filterpaper, the paper was dipped in buffer solution with $I_{\%}^{\circ}$ human albumin in order to avoid adsorption of labelled proteins on the filter paper. Barbital buffer of $\mathrm{pH} 8.6$ was used. The air-dried diagrams were used to make radio autograms.

Method 4. The juice was unconcentrated but otherwise the conditions were those given by GLASs et al. ${ }^{21}$ (preliminary dialysis, buffer of $\mathrm{pH} 9.0$, etc.). The proteins were labelled with radio-iodine as described above.

RESLLIS AND HISCLSSION

Saliva

The diagrams obtained with whole saliva from normal adults are shown in Fig. I.

With Method I, poor diagrams were obtained. The material at the base line is mainly visible mucus. Two or three fractions are noted. Method 2 (Grass) gave a much better separation and five fractions are visible. Method 3, using fresh, unconcentrated saliva, labelled with radio-iodine, gave results superior to those obtained with the other methods. Nine fractions are generally found, besides smaller discontinuities in the densitometric readings, that might originate from subfractions. The 3 fractions under 2 (Fig. I c) are rather variable. The fractions I, 3, 4 and 5 are much more stable. Fraction 6 is missing in various samples. Some of the fractions under 2 , 
and also fraction 6 are lost after preliminary dialysis of the saliva sample. They might be dialysable polypeptides. This fact, together with denaturation at higher pH values may explain the poor results with Method 4. Method 3 was used exclusively in our further studies.

Technical notes. No differences could be found between samples kept in ice and those kept at room temperature, even for $24 \mathrm{~h}$. Frozen samples at pH 8.5 could be stored at least a fortnight without detectable deterioration. For Methods I and 2, freeze-dried samples gave better results than those concentrated with the aid of strong colloid solutions. Filterpaper having larger pores gave slightly better results than Whatmann No. I, but the loose structure presented more difficulty at staining.

No quantitative conclusions may be drawn from the diagrams of Fig. I c, because the density of the bands not only depends upon the protein concentration but also upon the tyrosine (and histidine) content of the protein fractions, because iodination takes place mainly at these sites. The dotting at the base line is mainly due to dust particles, loaded with radio active iodide and difficult to avoid.

a

b

$\mathrm{c} \quad \mathrm{d}$

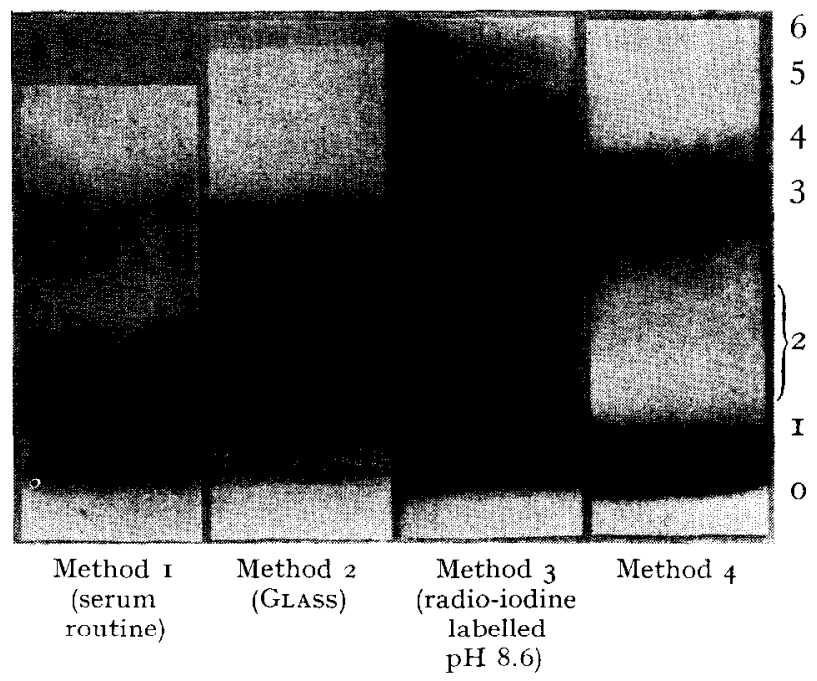

Fig. 1. Saliva.

With carbohydrate stain, 3 fractions are revealed. The one at the base line represents the visible mucus; the second one coincides with the place where the amylase activity is concentrated (Fig. $3 \mathrm{~d}$ ).

Finally it was noted that increasing concentration of the saliva sample gave a decrease in the number of bands. At high concentration, only two fractions were seen. This suggests the association of the protein molecules.

Physiological and pathological data. Although absolute quantitities of the various components could not be studied, changes in the concentrations under various conditions may be followed if the technique is standardised. The relation between the various constituents may be measured as relative densities of the bands. These may be translated into relative protein concentrations as soon as the binding capacity 
for ${ }^{131}$ I of each component is known. With method 3 , in this way ${ }_{5} 5$ samples of whole saliva of normal adults were measured. The samples were taken about $2 \mathrm{~h}$ after breakfast. They are compared with the results of 4 samples, collected in the early morning after ro $\mathrm{h}$ fasting. Another 6 samples were studied, that were obtained after stimulation (chewing on some quartz sand). The results are given in Table I.

TABLF I

\begin{tabular}{|c|c|c|c|c|c|c|}
\hline Fraction No. & $I$ & 2 & 3 & 4 & 5 & \\
\hline Mean of 1.5 "fasting" saliva samples & 3.5 & $2 \mathrm{I}$ & I 1 & 25 & 8 & rel. $\%$ \\
\hline Standard deviation & $5 \cdot 3$ & 3.2 & 2.1 & 5.1 & 4.0 & \\
\hline Early morning saliva samples. Mean of 4 & 19 & 26 & I I & 35 & 10 & rel. $\%$ \\
\hline "Rinsing" saliva, mean of 6 samples & $3^{8}$ & 20 & II & 23 & 8 & rel. $\%$ \\
\hline
\end{tabular}

Fraction o (Fig. Ic) was disregarded in the measurements owing to the disturbances at the base line. In some instances (5 times in 25 samples) 2 of the fractions were not adequately separated and were taken together. From Table I it is clear that the protein fractions of saliva are not as stable as those of the blood serum. Standard deviations are much greater than those found with serum proteins in comparable solution, by the same method. Although the numbers are still small, the results strongly suggest that "fasting saliva" during the day has a constitution that closely

a

b $c$

d

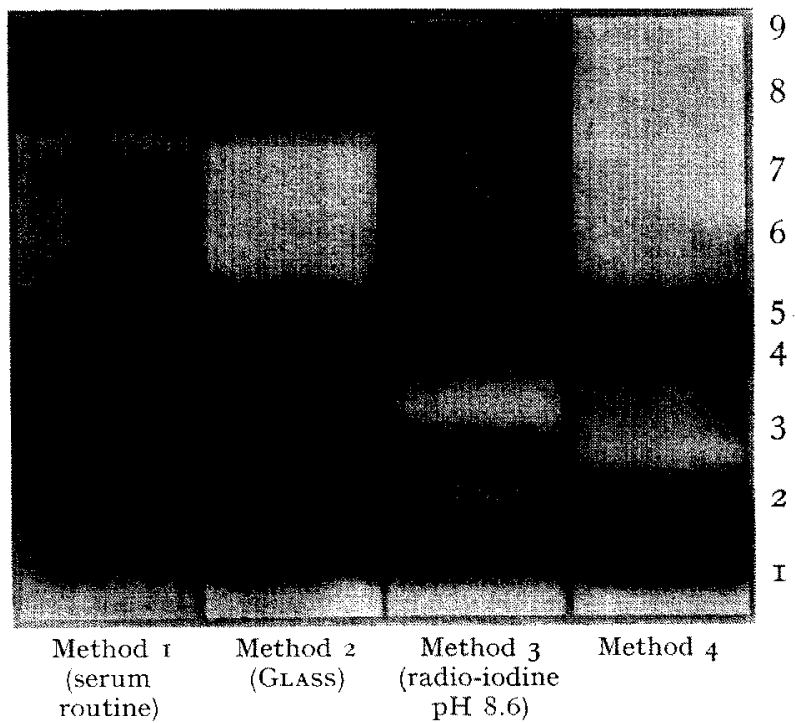

Fig. 2. Gastric juice.

resembles that of the "rinsing" saliva and differs significantly from the "resting" saliva taken early in the morning before breakfast, and before talking or other activities. This is especially clear for the fractions I and 4.

The study of the pathology of saliva proteins is at an elementary stage. We noted changes in the proportion of the 5 main fractions, the appearance of extra bands and of split bands in cases of stomatitis, acute pancreatitis, hepatitis, obstructive jaundice 
and pernicious anaemia. Much work has yet to be done before definite conclusions may be drawn.

\section{Gastric juice}

The data in this paper are restricted to normal fasting gastric juices. Diagrams, obtained with the 4 methods are given in Fig. 2.

Method I, with strongly concentrated gastric juice, gives blurred broad bands, showing 3 to 5 fractions. In our hands, Method 2 did not give as good results as those obtained by GLASS himself, although the diagrams were much better than those of Method I. Association of proteins at higher concentration, as had already been noticed in saliva, was obvious in both Method I and 2. Method 3 again gave the best separation and was less time consuming. Special care must be taken to bring the juice at pH 8.5 directly before iodination. This must be done with o.I $N$ NaOH. 8 to I I fractions can be distinguished in most of the diagrams. A very small portion of the material moves towards the anod, as has already been noted by GLAss. This quantity is too small to be seen in the reproduction of the diagram in Fig. 2 c. Method 4 gave disappointing results and was abandoned.

Technical notes. Contamination of the gastric juice with saliva interferes greatly with the results and had to be avoided by draining the saliva, e.g. by dental tampons.

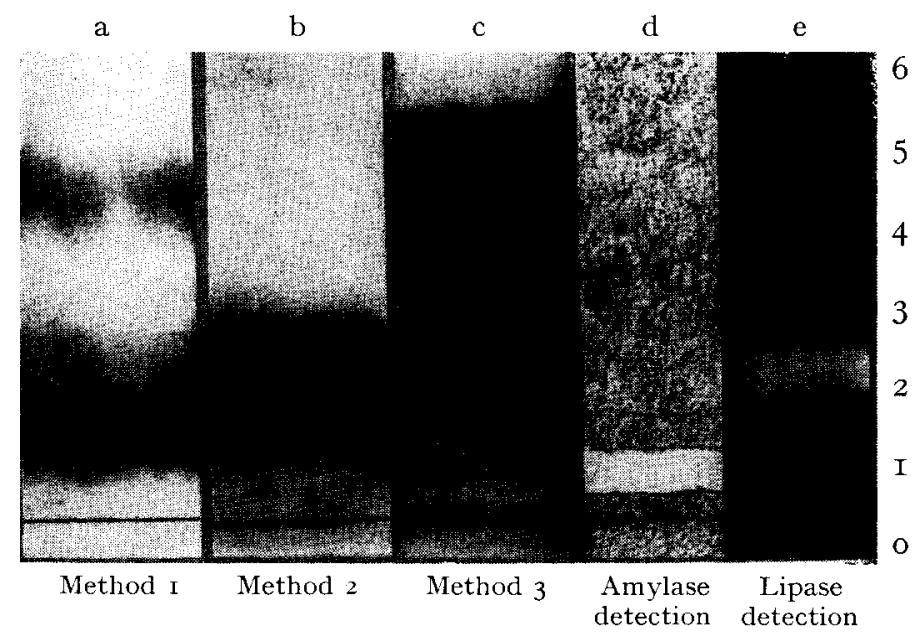

Fig. 3. Pancreatic juice.

The most important observation seems to be that concentration of the gastric juice results in a decrease of the number of bands that may be found, which intimates the association of proteins. This drawback is avoided by Method 3, as the labelling of proteins with radio-iodine allows very small quantities of proteins to be separated. Thus, a protein concentration of about $25 \mathrm{mg} \%$ is sufficient.

With the carbohydrate stain, 2 to 3 fractions are found, one at the base line with the appearance of coagulated mucus and one at the place of fraction 2 (Fig. $2 \mathrm{c}$ ). Often a third fraction is present with somewhat higher mobility.

The lipid stain gives negative results. Peptic activity was found to be strongest in the faster moving fractions. 
Bile

The diagrams of bile samples differ essentially from those obtained with saliva and gastric or pancreatic juice. The results were reported in separate communications ${ }^{22}, 23$.

\section{Pancreatic juice}

A number of samples of human pancreatic juice from two patients with pancreas fistulas were studied. Comparative results with various methods are given in Fig. 3 .

With Method I, in unconcentrated samples 5 very faint bands are barely visible. Concentration up to $2 \%$ proteins shows diagrams with 3 bands. Stronger concentrations, up to Io $\%$ or even $25 \%$, give diagrams with only 2 strongly stained broad bands, once more giving evidence of protein association. Method 2 lacks the ability of adequately fractionating, apparently as a result of the above mentioned protein association. With Method 3, in strongly diluted solution (the juice was diluted with I or 2 vol. water), good resolution is found and 7 fractions are seen. Diagrams $3 \mathrm{~d}$ and 3 e show the results of the detection methods for amylase and lipase. The main proteolytic activity is found before the lipase activity. The mucus component at the base line is practically missing in the pancreatic juice. The carbohydrate stain is much weaker than in the saliva and gastric juice diagrams. Only in concentrates of $25^{\circ} \%$ total solutes is a faint positive stain obtained. The lipid stain is negative.

Physiological datx. The dry weight of 23 portions of human pancreatic fistula juice varied between 0.75 and $1.57 \mathrm{~g} \%$ with a mean value of $1.30 \mathrm{~g} \%$. No constant difference between day and night portions was found. However, amylase production during the day was somewhat higher than during the night. In 23 portions it was found to lie between 3072 and $2288 \mathrm{U}$ (WoHLGEMUTH). The lipase content was very inconstant, varying between 0.9 and $28 \mathrm{U}$.

The total protein contents in I9 portions varied between 35 and $220 \mathrm{mg} \%$, with a məan value of $130 \mathrm{mg} \%$ (by nephelometry and the micro-Kjeldahl method).

\section{SUMMARY}

Conditions were studied for the optimal routine separation of the proteins in saliva, gastric juice, bile and pancreatic juice by paper electrophoresis. From an experiment with more than 5000 electrophoresis diagrams, a method was developed (Method 3), using very small samples of fresh unconcentrated or even diluted juices, in which the proteins were labelled with ${ }^{131} \mathrm{I}$ before paper electrophoresis. A quantity of 3 to $5 \mu \mathrm{g}$ proteins is sufficient for each separation. The method is described in detail. Results are shown in saliva, gastric juice and pancreatic juice. 9 , I I and 7 fractions respectively, were generally found. Comparison with methods in which the juices have to be concentrated considerably suggest strongly that such high concentration may give rise to the association of the protein molecules, thus invalidating more or less the results of the separation.

After having worked out a standard method, patterns were obtained that were sufficiently constant to give "normal values". This is demonstrated for saliva. However, split bands, small subfractions and small extra bands frequently appeared. The significance of such changes is not yet clearly understood.

Rifichoses $p .45$ 
The protein patterns of saliva, gastric and pancreatic juice have much in common. The mucus and mucoid substances are richest in the juices that come into contact with solid foodstuffs, suggesting that they have a mechanical function.

\section{REFERENCES}

1 A. J. ReID, Thesis, University of Alabama, 1952.

2 T. Kinersley, Yale J. Biol. and Med., 26 (1953) 2 II.

3 B. Drevon and R. Donilian, Compt. vend. soc. biol., 150 (1956) 1206.

4 J. R. PAtTon, Thesis, University of Alabama, 1956.

5 J. R. Patton and W. Pigman, Science, r25 (1957) 1292.

6 W. Pigman, J. Am. Dental Assoc., 54 (1957) 469.

3 L. Zipkin, E. R. Adamik and H. A. Saroff, Proc. Soc. Expll. Biol. Med., 95 (1957) 69.

8 B. C. Pugh, G. B. J. Glass and S. Wolff, Proc. Soc. Expll. Biol. Med., 79 (1952) 674.

9 R. F. Schilling. Proc. Soc. Exptl. Biol. Med., 83 (ig.53) 506.

111. A. L. Latner and C. C. Ungley, Brit. Med. J., (1953,I) 467 .

11 A. L. Grossberg, B. A. Komarov ano K. Shay, Am. J. Physiol., I65 (195 I) I.

12 L. Norpoth, J. Cloesges, M. Finger and M. Schultze, Deut. Med. Wochschy., 77 (1952) 563.

13 N. Henning and H. Kinzlmeier, Deut. Med. Wochschr., 77 (19.52) 998.

14 M. H. Mack, S. WOLfF AND K. Stern, J, Clin. Invest., 32 (I953) 862.

15 L. Torpoth, T. Surman and J. Cloesges, Klin. Wochschy., 3 I (1953) 1005.

16 R. Grassbeck, Gastroentevologia, 84 (1955) 99.

17 S. Rambaran Mishre, Thesis, State University, Utrecht, I9.5.

18 G. B. J. Glass, L. Stephanson and M. Rich, Federation Proc., 15 (1956) 75.

19 Korchi Shinoda, Nippon Naikagakkai Zasshi, 45 (1956) 348.

20 G. Barragallo-Sangrorgi, Minerva gastroenteyol, 2 (1956) 20.

21 G. B. J. Glass, L. Stephanson and M. Rich, Gastroenterologia, 86 (19.56) 384.

22 J. C. M. Verschure, Clin. Chim. Acta, I (1956) $3^{8}$.

23 J. C. M. Verschure AND P. F. MijnLLefF, Clin. Chim. Acta. I (1956) I 54.

24 P. Dessi and R. Pellegrini, Klin. Wochschr., 35 (1957) 34.

25 P. Dessi And M. Cresti, Boll. soc. ital. biol. sper., 33 (1957) 495.

26 M. P. Munro and J. E. Thomas, Am. J. Physiol, 145 (1945) I40.

27 G. M. Byrne, J. I. Phinney, M. Schachter and E. G. Young, J. Biol. Chem, I92 (I951) 683

28 A. L. Grossberg, S. A. Komarow and H. Shay, Am. J. Physiol, 168 (1951) 269.

29 H. A. RothsCHLD AND L. C. U. JANGUElRA, Nature, 178 (1956) 258.

30 Masayoshi Shigyo, Fukuoka-Igaku Zasshi, $4^{8}$ (1957) I23.

31 E. KoÏW And A. Grönwall, Scand. J. Clin. \& Lab. Invest., 4 (1952) 244.

32 C. B. Laurell and Ni. Skoog, Scand. J. Clin. E Lab. Invest., 8 (1956) 2 r.

33 N. Veall, J. D. Pearson and T. Hanley, Brit. I. Radiol., 28 (1955) 633.

34 O. P. Foss, Scand. J. Clin. E Lab. Invest., to, suppl. 31 (1957) 269.

35 W. L. Hughes, Ann. N. Y. Acad. Sci., 70 (1957) 3. 